\title{
A Multi-Nuclear MAS-NMR Study on the Structural Properties of Silicalite-1 Zeolite Synthesized Using N- and P-Based Organic Structure Directing Agents
}

\author{
Joaquin Martinez-Ortigosa (D), Jorge Simancas, Jose A. Vidal-Moya (D, Fernando Rey, Susana Valencia*(D) and \\ Teresa Blasco *(D)
}

check for

updates

Citation: Martinez-Ortigosa, J.; Simancas, J.; Vidal-Moya, J.A.; Rey, F.; Valencia, S.; Blasco, T. A MultiNuclear MAS-NMR Study on the Structural Properties of Silicalite-1 Zeolite Synthesized Using N- and P-Based Organic Structure Directing Agents. Appl. Sci. 2021, 11, 6850. https://doi.org/10.3390/app11156850

Academic Editors: Sibele Pergher and Katia Bernardo-Gusmão

Received: 1 June 2021

Accepted: 21 July 2021

Published: 26 July 2021

Publisher's Note: MDPI stays neutra with regard to jurisdictional claims in published maps and institutional affiliations.

Copyright: (C) 2021 by the authors Licensee MDPI, Basel, Switzerland. This article is an open access article distributed under the terms and conditions of the Creative Commons Attribution (CC BY) license (https:// creativecommons.org/licenses/by/ $4.0 /)$
Instituto de Tecnología Química (UPV-CSIC), Universitat Politècnica de València, Consejo Superior de Investigaciones Científicas, Av. de los Naranjos s/n, 46022 Valencia, Spain; joaquinmartinezortigosa@gmail.com (J.M.-O.); jorsico@itq.upv.es (J.S.); svidal@itq.upv.es (J.A.V.-M.); frey@itq.upv.es (F.R.)

* Correspondence: svalenci@itq.upv.es (S.V.); tblasco@itq.upv.es (T.B.)
Abstract: The nature of organic structure directing agents (OSDAs) is of paramount importance in the final properties of zeolites, particularly the framework and porosity. Recently, the use of P-containing OSDAs has been employed for new zeolites, but there is little discussion compared to their analogues N-OSDAs. The main objective of this work is the characterization of pure silica MFI zeolite (silicalite-1) prepared by the dual-template route with tetrapropylammonium (TPA), tetrapropylphosphonium (TPP) cations, and mixtures thereof aiming to understand by advanced NMR methods how the nature of the organic influences the physico-chemical properties of the zeolite. Silicalite-1 has been successfully synthesized using the dual-template procedure with TPA and TPP molecules. Both OSDAs are incorporated into the zeolite without any specific preference, differently to that observed before for the TEA/TEP system, and homogenously mixed inside of the zeolite voids. The presence of TPP leads to the incorporation of less F, raising the concentration of $\mathrm{Q}^{3}$-defective sites in the silicalite- 1 zeolites. Detailed NMR results indicate that those structural defects are close to the $-\mathrm{CH}_{3}$ group of the entrapped OSDAs in the zeolite and these defects consist of at least two silanol groups stabilizing the $\mathrm{Si}^{-} \mathrm{O}^{-}$species, which is responsible for the charge balancing.

Keywords: P-based OSDAs; zeolites; solid state MAS-NMR

\section{Introduction}

Zeolites are crystalline microporous materials typically in aluminosilicate composition whose structures are formed by silicon and aluminum tetrahedra linked by corner-sharing oxygen atoms. These tridimensional structures generate channels and cavities of molecular dimensions leading to materials largely utilized in industrial applications, such as catalysis, adsorption, and ion exchange, among others [1-3]. Their well-defined porosity, thermal stability, and the possibility of modifying the chemical composition and properties account for the success of these materials [4-8].

Zeolites exist in nature as low $\mathrm{Si} / \mathrm{Al}$ ratio materials, and can be synthesized in a wide range of chemical compositions from $\mathrm{Si} / \mathrm{Al}$ ratios of 1 up to purely siliceous, and also incorporating other elements, thus generating an extensive variety of materials with diverse properties [9]. Purely siliceous zeolites are neutral materials, but the presence of $\mathrm{Al}$ in the framework generates a negative charge that must be compensated by cations that can be inorganic, organic, or protons. In the latter case, acidic sites are generated, and this is one of the main properties of zeolites that allows their application as catalysts in acid catalyzed processes [10-14].

Synthesis of zeolites is usually done in hydrothermal conditions starting from alkaline mixtures that contain the aluminosilicate precursors in which the hydroxyls mobilize the 
species in solution to build the final zeolite structure [15-18]. However, it is also possible to carry out the synthesis from fluoride containing synthesis mixtures wherein the fluoride anions play the mobilizing role [19-21]. Zeolites synthesized in fluoride medium generally contain a lower concentration of structural connectivity defects than their hydroxide counterparts, and fluorine tends to occupy the smallest cage present in the structure and compensates the positive charge of the organic cations [22,23].

High $\mathrm{Si} / \mathrm{Al}$ ratio zeolites are commonly synthesized using tetraalkylammonium cations as organic structure directing agents (OSDAs) that participate during the crystallization process and stabilize the zeolite structure by filling the pores and cavities [24-28]. These ammonium cations frequently undergo Hoffmann degradation in the highly alkaline medium that exists during the synthesis at high temperature and prolonged time, the use of tetraalkylphosphonium cations being an alternative route that has been successfully used in the last several years leading to the discovery of new zeolite structures [29-35].

ZSM-5 is one of the most widely applied zeolites as an acid catalyst for industrial processes in many reactions, such as fluid catalytic cracking, hydrocarbon isomerization and alkylation, methanol to olefins, among many others [36-40]. The distribution and location of $\mathrm{Al}$ in different crystallographic positions of the zeolite framework is highly relevant as it can affect the final catalytic properties and, specifically, ZSM-5 is one of the most studied zeolites in this regard [41-46]. In addition, the control of the acidity is of paramount importance for maximizing the activity of the catalyst that is frequently submitted to very high temperatures and leads to partial dealumination processes in which aluminum atoms migrate to extraframework positions with the subsequent decrease in the acidity. In relation to this, the stabilization of $\mathrm{Al}$ in framework sites by post-synthesis modification of the zeolite with phosphorous containing reactants has been reported [38,47-52]. These P-species interact with Al atoms and stabilize them in the structure when they are submitted to severe thermal or hydrothermal treatments [53,54]. As mentioned above, tetraalkylphosphonium cations can also be used as OSDAs in the synthesis of zeolites, and, in these cases, phosphorous remains inside the zeolite pores after the calcination process required for burning-off the organic material and plays the stabilizing role of $\mathrm{Al}$ in the framework [27,35,55-57]. Interestingly, the use of P-containing OSDAs favors a homogeneous distribution of $\mathrm{P}$ across the zeolite crystals and allows the control of the amount of $\mathrm{P}$ incorporated by means of the dual-template methodology for the synthesis of zeolites $[55,58,59]$. This approach consists of using two OSDAs of different nature, in this case, one containing phosphorous and the other nitrogen, thus modulating the $\mathrm{P} / \mathrm{Al}$ ratio of the zeolite and therefore its acidity. Figure 1 shows the location of the tetrapropylammonium cations in the MFI structure which are placed in the intersection of the two different channels that the structure has [60].

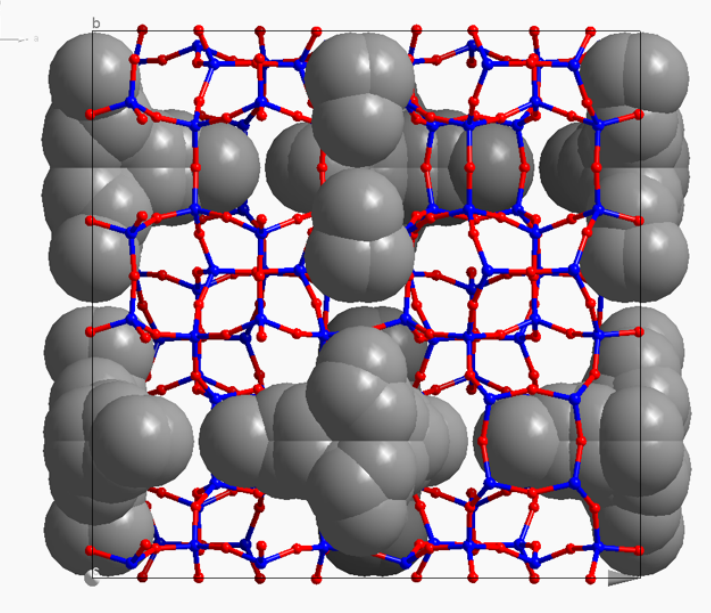

Figure 1. MFI structure containing the TPA molecules at the intersections of the channels. 
ZSM-5 is a medium pore size zeolite which has been assigned the three-letter code MFI by the International Zeolite Association (IZA), and its structure contains a sinusoidal channel along the $a$-axis that intersects with straight channels running along $b$ with pore apertures of $5.1 \times 5.5 \mathrm{~A}$ and $5.3 \times 5.6 \mathrm{~A}$, respectively [61]. The structure can be built by the linkage of four different Composite Building Units (CBUs) and contains a small cage, known as mel, which usually hosts the fluorine atoms incorporated when the synthesis is done in fluoride medium [62,63]. This zeolite can be synthesized in a wide range of chemical compositions and in the presence of a great variety of molecules as OSDAs or even in the absence of any organic, being the first case of an inorganic structure directing effect.

Recently, we have studied the synthesis of the pure silica MFI zeolite, known as silicalite-1, by applying the dual-template method using tetraethylammonium (TEA) and tetraethylphosphonium (TEP) cations in which both molecules operated as co-templates and the characteristics of the zeolites were modified by changing the TEA/TEP ratio inside of their channels [64]. In this work, we extend the synthesis of silicalite-1 using tetrapropylammonium (TPA) and tetrapropylphosphonium (TPP) cations and mixtures thereof as OSDAs, since TPA is the most used organic molecule for the synthesis of MFI materials, and it is worth studying their preparation in the presence of TPA/TPP.

Thus, the main objective of this work is the characterization of pure silica MFI zeolite (silicalite-1) prepared by the dual-template route with TPA, TPP, and mixtures of both cations in different ratios aiming to understand how the nature of the organic influences the physico-chemical properties of the zeolite. This study has been carried out by exhaustive characterization of the zeolites prepared with special emphasis on the use of solid state nuclear magnetic resonance techniques which are very powerful for this purpose. In particular, a multinuclear magic angle spinning-nuclear magnetic resonance (MAS NMR) analysis has allowed for investigating the framework structure, the status of the guest species located within the void volume of the zeolites, as well as the interaction between them. This MAS NMR study includes the resonance spectra of ${ }^{13} \mathrm{C},{ }^{1} \mathrm{H},{ }^{31} \mathrm{P},{ }^{29} \mathrm{Si}$, and ${ }^{19} \mathrm{~F}$ nuclei for the characterization of the guest species and the host zeolite, and bidimensional (2D) heteronuclear (HETCOR) and homonuclear (DQ-SQ) NMR experiments for shedding light on the interactions of the OSDAs with the zeolite. The results allow us to conclude that the dual-template route with TPA/TPP for the synthesis of MFI is achievable, both organics are hosted inside the pores forming a homogeneous mixture, and the concentration of structural defects (i.e., silanol groups) depends on the amount of P incorporated in the zeolite.

\section{Materials and Methods}

\subsection{Synthesis of Silicalite-1 Zeolites}

Silicalite-1 samples were prepared by hydrothermal synthesis in fluoride medium using tetraethylorthosilicate (TEOS, 99\%, Merck, Darmstadt, Germany) as the silica source, aqueous solutions of tetrapropylammonium hydroxide (TPAOH, 20\%, Aldrich, Darmstadt, Germany) and/or tetrapropylphosphonium hydroxide (TPPOH) and HF (48\%, Aldrich). TPPOH is not commercially available and was prepared by alkylation of tripropylphosphine (97\%, Aldrich) with 1-bromopropane (99\%, Aldrich) in anhydrous acetonitrile (99\%, Alfa-Aesar, Darmstadt, Germany) as solvent, in $\mathrm{N}_{2}$ atmosphere at room temperature for two days. The tetrapropylphosphonium bromide product was dissolved in Milli-Q water and exchanged to the hydroxide form in batch overnight using an anionic exchange resin (Amberlite IRN-78, Supelco, Darmstadt, Germany) to get the corresponding hydroxide (TPPOH).

The synthesis procedure consisted of the hydrolysis of TEOS in the aqueous solutions of TPAOH, TPPOH, or mixtures of them in different ratios, and stirring the solutions until complete evaporation of the ethanol produced in the hydrolysis together with the required amount of water to get the final water content. Finally, the HF solution was added and the mixture was homogenized. The general chemical composition of the synthesis gels was the following: 
$1 \mathrm{SiO}_{2}: 0.4$ OSDAOH:0.4 HF: $15 \mathrm{H}_{2} \mathrm{O}$

The gels were transferred into Teflon-lined stainless steel autoclaves and the crystallization was carried out at $175{ }^{\circ} \mathrm{C}$ under tumbling conditions (60 rpm) for times comprised between 7 and 12 days. The particular conditions for the samples prepared are summarized in Table 1, where the ratio of each OSDA is specified together with the synthesis time. In addition, the nomenclature of the samples is given in Table 1, where TPA-MFI and TPP-MFI stand for silicalite- 1 zeolites prepared using a unique OSDA source, i.e., $\mathrm{TPAOH}$ and TPPOH, respectively. On the other hand, silicalite-1 samples prepared using the dual-template method are named as TPX-MFI ${ }_{\mathrm{xx}}$, with $\mathrm{xx}$ being the molar percentage of TPP in the mixture of TPP/(TPP + TPA) incorporated in the zeolite.

Table 1. Detailed synthesis conditions of the silicalite- 1 samples prepared using TPA, TPP, and mixtures of them as OSDAs.

\begin{tabular}{|c|c|c|}
\hline Sample & OSDA $^{1}$ & Crystallization Time $^{2}$ (Days) \\
\hline TPA-MFI & $1.00 \mathrm{TPA} / 0.00 \mathrm{TPP}$ & 12 \\
\hline $\mathrm{TPX}-\mathrm{MFI}_{25}$ & $0.25 \mathrm{TPP} / 0.75 \mathrm{TPA}$ & 7 \\
\hline TPX-MFI 45 & $0.50 \mathrm{TPP} / 0.50 \mathrm{TPA}$ & 10 \\
\hline TPP-MFI & $0.00 \mathrm{TPA} / 1.00 \mathrm{TPP}$ & 7 \\
\hline
\end{tabular}

${ }^{1}$ Molar ratios. ${ }^{2}$ All the syntheses carried out at $175{ }^{\circ} \mathrm{C}$.

\subsection{Characterization Techniques}

The X-ray diffraction (XRD) patterns of the samples were measured in a Cubix'Pro diffractometer from Panalytical, using CuK radiation $\left(\lambda_{1}=1.5406 \mathrm{~A}\right)$ at $45 \mathrm{kV}$ and $40 \mathrm{~mA}$ in the $2 \theta$ range from 4 to $40^{\circ}$. The chemical composition of the samples was determined by inductively coupled plasma optical emission spectroscopy (ICP-OES) for analyzing $\mathrm{Si}$ and $\mathrm{P}$ in a Varian 715-ES device after dissolution of the solids in a mixture of acids $\left(\mathrm{HNO}_{3} / \mathrm{HF} / \mathrm{HCl}\right)$, and by elementary analysis $(\mathrm{EA})$ for the quantification of $\mathrm{C}, \mathrm{H}$, and $\mathrm{N}$ in a EuroEA3000 instrument from Eurovector. The thermogravimetric analyses (TGA) were measured in a Netzsch STA449 F3 Jupiter apparatus up to $800{ }^{\circ} \mathrm{C}$ at a heating ramp rate of $10^{\circ} \mathrm{C} / \mathrm{min}$ in air flow. The morphology and size of the crystals were evaluated by field emission scanning electron microscopy (FESEM) in a Zeiss Ultra-55 microscope equipped with an energy dispersive X-ray analyser (EDX). The P content was measured by EDX on multiple points of several MFI crystals. No significant differences in the P content were found, indicating the homogeneity of $P$ distribution across the MFI crystals.

MAS NMR experiments were done by using a Bruker Avance III HD $400 \mathrm{MHz}$ spectrometer. ${ }^{1} \mathrm{H} /{ }^{13} \mathrm{C} \mathrm{CP}$ MAS NMR was recorded with a $4.0 \mathrm{~mm}$ probe spinning the sample at $10 \mathrm{kHz}$, using a ${ }^{1} \mathrm{H} \pi / 2$ pulse length of $2.5 \mu$ s with SPINAL ${ }^{1} \mathrm{H}$ decoupling, 2 ms as contact time, and $3 \mathrm{~s}$ as recycle delay. ${ }^{1} \mathrm{H}$ MAS NMR spectra were carried out on a $3.2 \mathrm{~mm}$ probe at $20 \mathrm{kHz}$ spinning speed, $\pi / 2$ pulse length of $2.5 \mu \mathrm{s}$, and $15 \mathrm{~s}$ as recycle delay. 2D DQ-SQ ${ }^{1} \mathrm{H}$ MAS NMR experiments were done using the $2.5 \mathrm{~mm}$ probe spinning at $25 \mathrm{kHz}$, using a BABA-type pulse sequence with 2 rotor periods recoupling and a radiofrequency field of $100 \mathrm{kHz}$, rotor synchronized time evolution of $40 \mu \mathrm{s}$, and $3 \mathrm{~s}$ as a recycle delay. ${ }^{31} \mathrm{P}$ MAS NMR spectra were registered by using a $3.2 \mathrm{~mm}$ probe spinning at $20 \mathrm{kHz}$ using a $\pi / 2$ pulse length of $3.7 \mu$ s with SPINAL proton decoupling and recycle delay of $20 \mathrm{~s} .{ }^{19} \mathrm{~F}$ MAS NMR experiments were acquired with a $3.2 \mathrm{~mm}$ probe spinning the sample at $20 \mathrm{kHz}$, using a $\pi / 2$ pulse length of $4 \mu \mathrm{s}$ and $60 \mathrm{~s}$ recycle delay for quantitative analysis, done by integration of the signals, using an external reference with a known amount of fluorine. ${ }^{29}$ Si MAS NMR spectra were recorded by using a $7.0 \mathrm{~mm}$ probe with $3.5 \mu$ s pulse length corresponding to a $60^{\circ}$ flip angle, SPINAL proton decoupling, and $180 \mathrm{~s}$ as recycle delay. NMR spectra were referenced to TMS, $\mathrm{CFCl}_{3}$, adamantine, phosphoric acid, and water for ${ }^{29} \mathrm{Si},{ }^{19} \mathrm{~F},{ }^{13} \mathrm{C},{ }^{31} \mathrm{P}$, and ${ }^{1} \mathrm{H}$, respectively. The ${ }^{1} \mathrm{H}-{ }^{31} \mathrm{P}$ 2D HETCOR spectra were obtained using the $2.5 \mathrm{~mm}$ rotor spinning the sample at $25 \mathrm{kHz}$. The contact time was set to $3 \mathrm{~ms}$ and the recycle delay to $4 \mathrm{~s} .{ }^{1} \mathrm{H} \mathrm{CW}$ decoupling $\left(\nu_{\mathrm{RF}} \sim 50 \mathrm{kHz}\right)$ was applied during acquisition. 


\section{Results and Discussion}

\subsection{Synthesis of Silicalite-1 Zeolites}

The zeolite crystallization from the synthesis gels containing tetrapropylammonium (TPA), tetrapropylphosphonium (TPP), or mixtures thereof as OSDAs lead to the formation of pure silica MFI as the unique crystalline phase without any amorphous material, as confirmed by the XRD patterns shown in Figure 2. The X-ray diffractograms show slight differences in the relative intensities of the peaks at low angles, which can be attributed to the use of different OSDAs, and the peaks between $22^{\circ}$ and $26^{\circ}$ (see magnification, inset in Figure 2) are broader for the sample synthesized with TPP than that with TPA. These differences suggest that smaller crystals are formed when the TPP cation is used than in the presence of TPA.

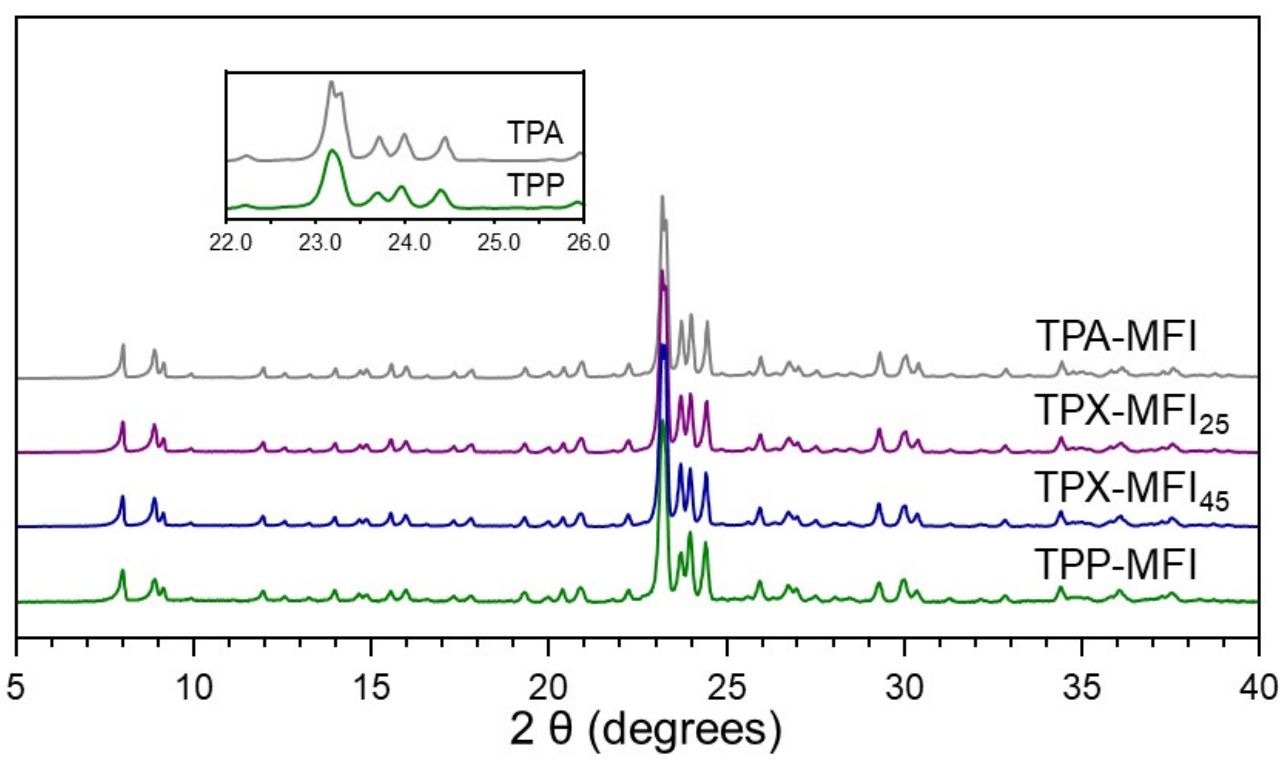

Figure 2. XRD patterns of silicalite-1 samples synthesized using TPA, TPP, and mixtures of them as OSDAs. The inset corresponds to the magnification of the range between $22-26^{\circ}$.

The chemical composition of the silicalite- 1 samples is displayed in Table 2. The $\mathrm{P} /(\mathrm{P}+\mathrm{N})$ molar ratio contained into the zeolites synthesized using mixtures of TPP and TPA cations is close to that employed in the synthesis gel. This result indicates that, contrary to the observations for the silicalite- 1 samples synthesized using mixtures of TEP/TEA, there is no preferential incorporation of phosphonium over ammonium cations in the zeolite [64]. Independently from the organic cation used in the synthesis, all silicalite-1 samples contain about four molecules of OSDA per unit cell. All silicalite-1 samples contain a F/OSDA molar ratio below 1, indicating that they must contain $\mathrm{SiO}^{-}$defects to completely balance the positive charge introduced by the organic molecules. $\mathrm{The}^{\mathrm{SiO}}{ }^{-}$ defect concentration in the silicalite- 1 increases as the occluded TPP inside of zeolite sample does.

Table 2. Chemical composition of the silicalite-1 samples prepared using TPA, TPP, and mixtures of them as OSDAs.

\begin{tabular}{cccccc}
\hline Sample & $\mathbf{P} /(\mathbf{P}+\mathbf{N})^{\mathbf{1}}$ Gel & $\mathbf{P} /(\mathbf{P}+\mathbf{N})^{\mathbf{1}}$ Solid & $\begin{array}{c}\text { OSDA/ } \\
\text { u.c. }{ }^{2}\end{array}$ & F/u.c. ${ }^{3}$ & F/OSDA \\
\hline TPA-MFI & 0.00 & 0.00 & 4.5 & 3.3 & 0.74 \\
TPX-MFI $_{25}$ & 0.25 & 0.26 & 4.1 & 2.6 & 0.64 \\
TPX-MFI $_{45}$ & 0.50 & 0.45 & 4.1 & 2.5 & 0.60 \\
TPP-MFI $^{2}$ & 1.00 & 1.00 & 4.3 & 2.4 & 0.56 \\
\hline
\end{tabular}

${ }^{1}$ Molar ratios. ${ }^{2} 96 \mathrm{Si}$ atoms per unit cell $\left(\mathrm{Si}_{96} \mathrm{O}_{192}\right) \cdot{ }^{3}$ Quantified by ${ }^{19} \mathrm{~F}$ MAS-NMR. 
Figure 3 shows images of the silicalite- 1 samples obtained by FESEM, which shows a homogeneous distribution of crystal sizes which are notably smaller for the TPP-MFI $(1 \mu \mathrm{m} \times 0.5 \mu \mathrm{m} \times 0.2 \mu \mathrm{m})$ than for the TPA-MFI sample $(10 \mu \mathrm{m} \times 5 \mu \mathrm{m} \times 1 \mu \mathrm{m})$, in agreement with the differences observed in the XRD patterns (see inset in Figure 2). Crystals of intermediate sizes are observed for the TPX-MFI 25 and TPX-MFI 45 zeolites synthesized with mixtures of OSDAs. It is worth noting that the morphology of the crystals is different from those synthesized with TEP/TEA, which are more elongated and narrower, presenting the typical coffin-shape [64].
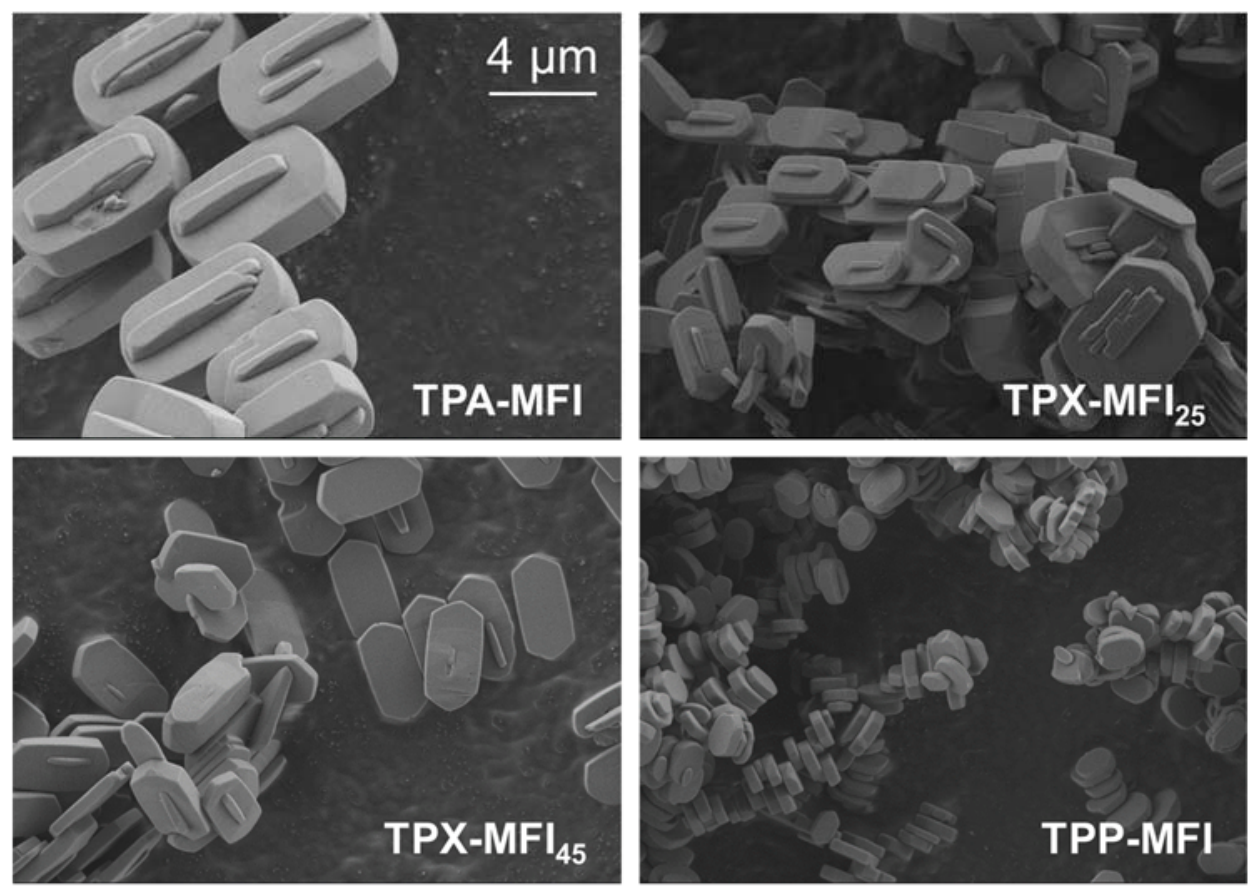

Figure 3. FESEM images of silicalite-1 samples synthesized using TPA, TPP, and mixtures of them as OSDAs. Scale bar stands for all images.

Additionally, the analysis of the P content in the TPX-MFI 25 and TPX-MFI 45 samples by FESEM-EDX was verified in several crystals to be $0.6 \pm 0.1 \mathrm{wt} . \% \mathrm{P}$ and $1.1 \pm 0.2 \mathrm{wt} . \% \mathrm{P}$, respectively. These values are fully consistent with those obtained by ICP analysis, indicating that the two types of OSDA molecules are well distributed along the MFI crystals supporting their co-templating effect during the zeolite crystallization.

The thermal stability of the organic cations within the zeolite porosity was determined by the thermogravimetric analyses, shown in Figure 4. The TPA-MFI zeolite shows a unique 12.5 wt.\% weight loss around $430{ }^{\circ} \mathrm{C}$, whereas, for the TPP-MFI sample, its $10.5 \mathrm{wt} \%$ weight loss occurs at approximately $510{ }^{\circ} \mathrm{C}$, demonstrating the higher thermal stability of the phosphorous cations inside the zeolite. The TPX-MFI 25 zeolite presents a $11.5 \mathrm{wt} . \%$ weight loss, with the main peak at $435{ }^{\circ} \mathrm{C}$, and a less intense peak between $505-510{ }^{\circ} \mathrm{C}$, while the TPX-MFI 45 sample exhibits a $11 \mathrm{wt}$.\% weight loss with the main peak at $455{ }^{\circ} \mathrm{C}$ followed by a peak around $505{ }^{\circ} \mathrm{C}$, that is, the thermal decomposition of TPA shifts to higher temperatures due to the presence of TPP, indicating a higher thermal stability. In addition, the weight loss decreases as TPP content increases due to the phosphorous oxide remaining inside the materials upon calcination. The combustion of the organic material is an exothermic and complex process, and it is possible that the heat produced during burning of TPA helps in the combustion of the closer TPP cations (occurring at higher temperature), leading to a lower temperature in the TGA-DTG. The shifts of the TPA peak towards higher temperatures and of the TPP peak towards lower temperatures suggests the coexistence of both TPA and TPP inside the ZSM-5 channels. 


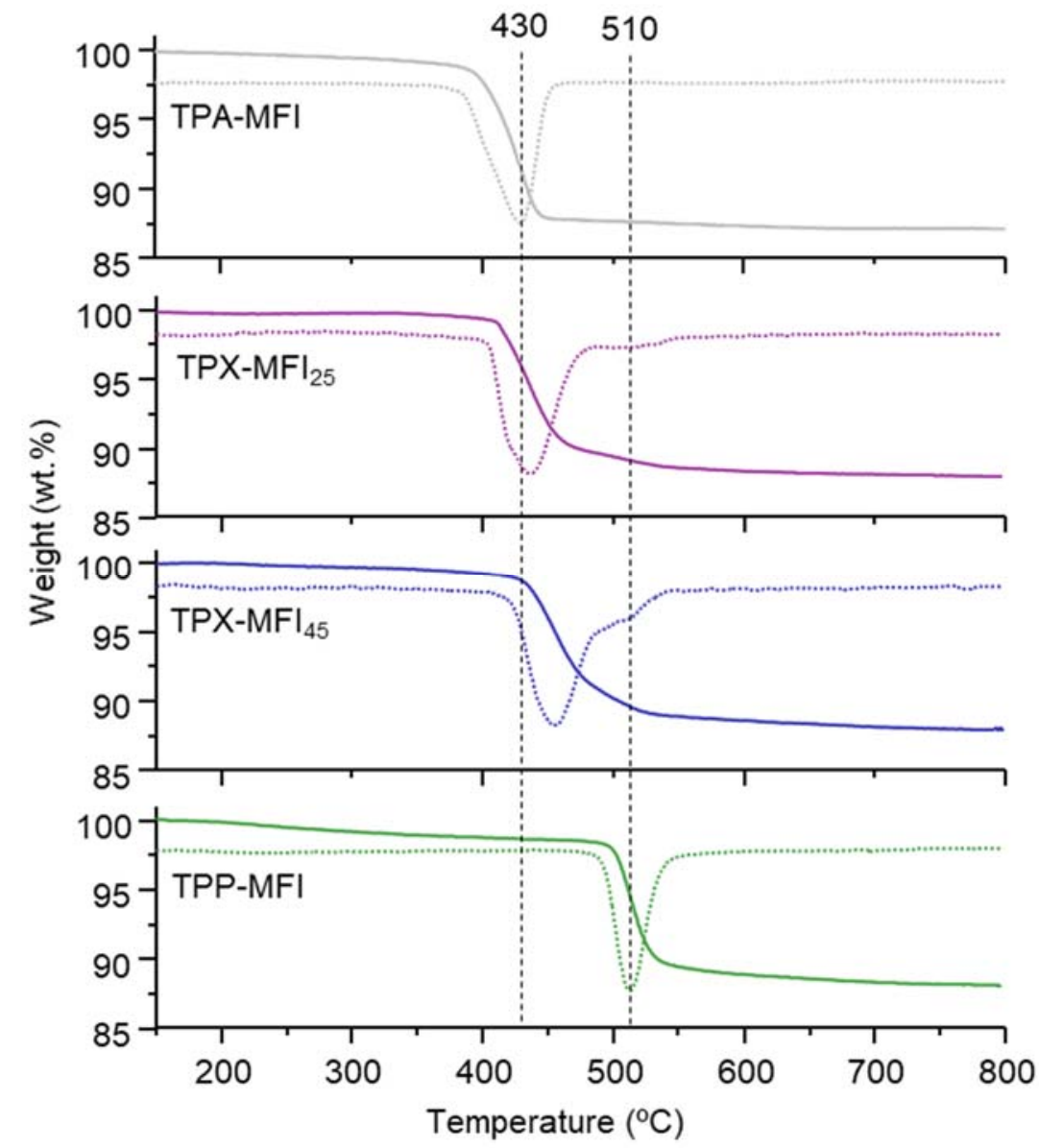

Figure 4. TGA-DTG analyses of silicalite-1 samples synthesized using TPA, TPP, and mixtures of them as OSDAs. Solid lines stand for TGA curves and dashed ones for DTG.

These results allow concluding that the synthesis of silicalite- 1 zeolites using the dualtemplate procedure with TPA and TPP cations is feasible and the crystal size of the zeolites decreases when phosphorous agents are used under the synthesis conditions studied.

\subsection{Structural Characterization of Silicalite-1 Zeolites by MAS NMR Spectroscopy}

To have a better understanding on the structural features of the zeolites, a more complete characterization was carried out, mainly focused on the use of NMR spectroscopy, to get insight, on the one hand, into the inorganic zeolite framework structure. On the other hand, NMR spectroscopy sheds light on the status of the guest species (OSDA and fluoride) located within the pores of the host zeolite and the interactions between them.

\subsubsection{Characterization of the Framework and Guest Species}

The organic material incorporated in the zeolites was characterized by measuring the corresponding NMR spectra of the different nuclei $\left({ }^{1} \mathrm{H} /{ }^{13} \mathrm{C} \mathrm{CP},{ }^{31} \mathrm{P}\right.$ and $\left.{ }^{1} \mathrm{H}\right)$ of the samples synthesized with TPP and/or TPA. The ${ }^{1} \mathrm{H} /{ }^{13} \mathrm{C}$ CP MAS NMR spectra of the zeolites prepared are shown in Figure 5. 


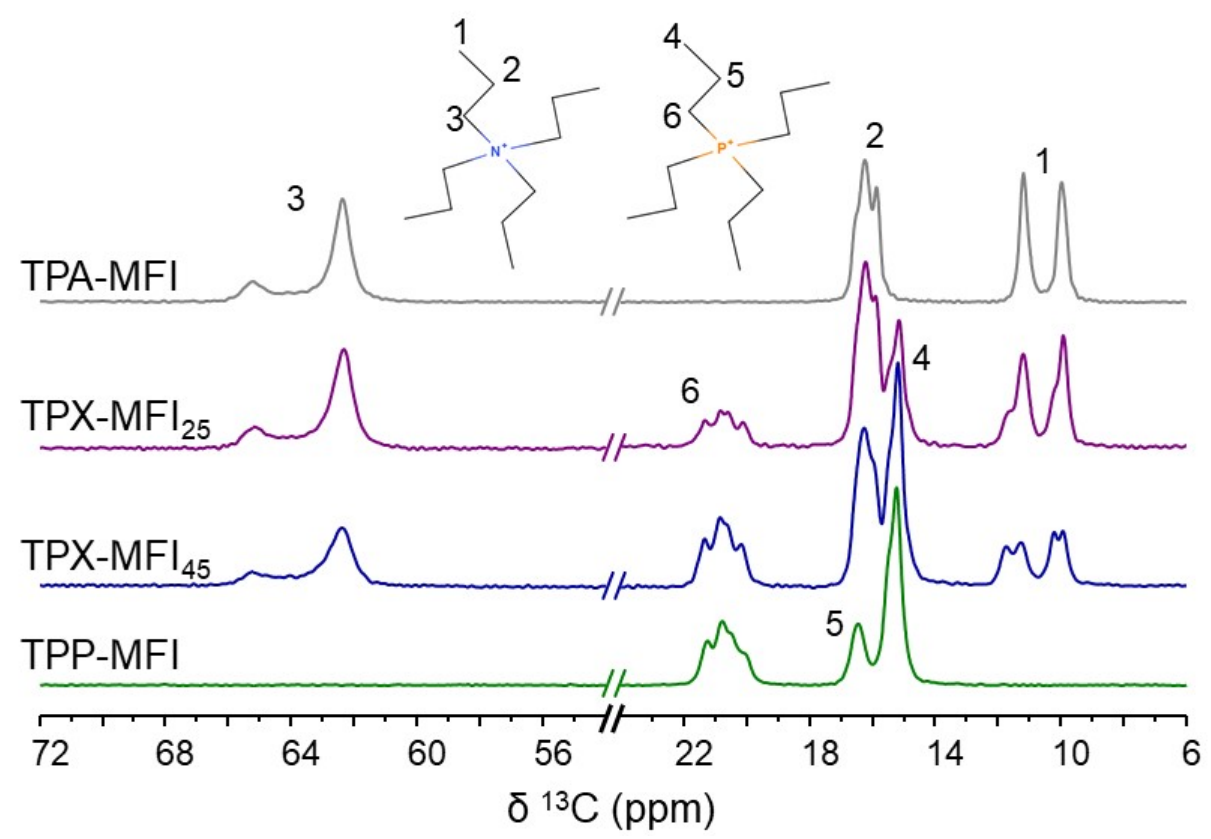

Figure 5. ${ }^{1} \mathrm{H} /{ }^{13} \mathrm{C} C \mathrm{CP}$ MAS NMR spectra of silicalite-1 samples synthesized using TPA, TPP, and mixtures of them as OSDAs.

The ${ }^{1} \mathrm{H} /{ }^{13} \mathrm{C} C P$ MAS NMR spectrum of the TPA-MFI zeolite contains three groups of signals at: (1) $\delta^{13} \mathrm{C}=10.0 \mathrm{ppm}$ and $\delta^{13} \mathrm{C}=11.3 \mathrm{ppm}$ due to the $-\mathrm{CH}_{3}$ groups that are attributed to the orientation of the alkyl chains towards the sinusoidal and straight channels, respectively; (2) a group of signals at around $\delta^{13} \mathrm{C}=16.0 \mathrm{ppm}$ corresponding to the $-\mathrm{CH}_{2}-$ groups, indicating that there are slight differences regarding their local environment, probably due to the orientation of the alkyl chain to one channel or another; and (3) two signals around $\delta^{13} \mathrm{C}=64.0 \mathrm{ppm}$ with a 1:3 ratio corresponding to the $\mathrm{N}-\mathrm{CH}_{2}-$ group, which have been previously attributed to the angular deformation (NCC or NCCC) of the alkyl chains of the OSDA $[65,66]$.

The ${ }^{1} \mathrm{H} /{ }^{13} \mathrm{C} C P$ MAS NMR spectrum of the TPP-MFI zeolite shows three groups of signals at $\delta^{13} \mathrm{C} \approx 15.5 \mathrm{ppm}, \delta^{13} \mathrm{C} \approx 17.0 \mathrm{ppm}$, and $\delta^{13} \mathrm{C} \approx 21.0 \mathrm{ppm}$, corresponding to the $-\mathrm{CH}_{3},-\mathrm{CH}_{2}-$, and $-\mathrm{CH}_{2}-\mathrm{P}$ groups of the TPP cation, respectively. The asymmetric shape of the $-\mathrm{CH}_{3}$ group signals, which contains two components, can be attributed to the different orientation of the alkyl chains in the sinusoidal and straight channels of the material analogously to that observed in TPA-MFI. Finally, a group of four signals appears at $\delta^{13} \mathrm{C} \approx 21.0$ resulting from the overlapping of two doublets of the $\mathrm{P}-\mathrm{CH}_{2}-$ group, due to the scalar $\mathrm{J}$ coupling between ${ }^{31} \mathrm{P}$ and ${ }^{13} \mathrm{C}$ atoms of the two chains oriented to each channel.

The ${ }^{1} \mathrm{H} /{ }^{13} \mathrm{C} C P$ MAS NMR spectra of the TPX-MFI ${ }_{X X}$ samples contain the signals coming from the TPA and TPP described above. However, the splitting of the signal of the $-\mathrm{CH}_{3}$ groups of TPA is remarkable and depends on the amount of TPP incorporated in the zeolite. This result indicates that the presence of TPP directly influences the chemical shift of the $-\mathrm{CH}_{3}$ groups of TPA by modifying their environment and strongly supports the coexistence of both cations in the MFI crystals.

The zeolites synthesized in the presence of the P-containing OSDA were also studied by measuring the ${ }^{31}$ P MAS NMR spectra, which are shown in Figure 6a. They consist of slightly asymmetric signals at $\delta^{31} \mathrm{P} \approx 30.0 \mathrm{ppm}$ indicating the existence of more than one ${ }^{31} \mathrm{P}$ environment, in agreement with the splitting of the $-\mathrm{CH}_{2}-\mathrm{P}$ signals in the ${ }^{1} \mathrm{H} /{ }^{13} \mathrm{C} \mathrm{CP}$ MAS NMR shown in Figure 5. The ${ }^{31} \mathrm{P}$ signal of TPP is shifted in the zeolites containing also TPA supporting the coexistence of both cations in the zeolite crystals and that one affects the other. 
a)

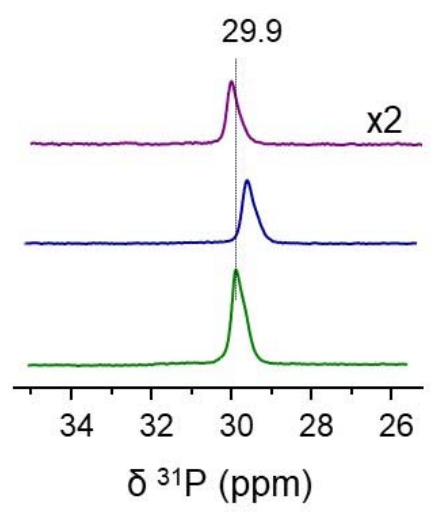

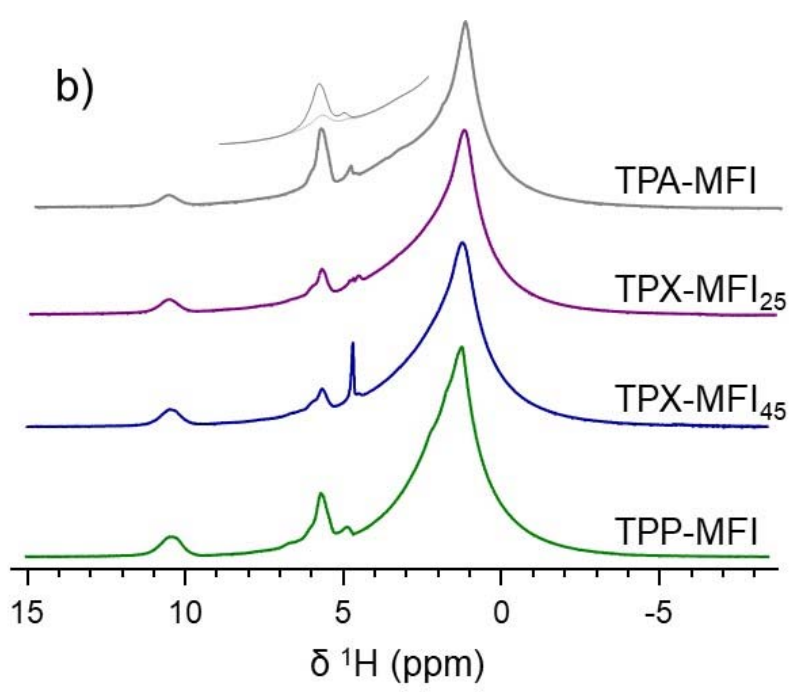

Figure 6. ${ }^{31} \mathrm{P}$ and ${ }^{1} \mathrm{H}$ MAS NMR spectra of silicalite-1 samples synthesized using different OSDAs: (a) ${ }^{31}$ P MAS NMR spectra of the zeolites prepared using TPP and TPP/TPA mixtures; (b) ${ }^{1} \mathrm{H}$ MAS NMR spectra of the zeolites prepared using TPP, TPA, and mixtures of them. Amplification corresponds to the evacuation of the TPA-MFI sample in the NMR rotor under mild conditions $\left(100^{\circ} \mathrm{C}, 10 \mathrm{~h}\right)$.

The ${ }^{1} \mathrm{H}$ MAS NMR spectra displayed in Figure $6 \mathrm{~b}$ contain a broad signal between $\delta^{1} \mathrm{H}=0-4 \mathrm{ppm}$ with the maximum at $\delta^{1} \mathrm{H} \approx 1.4 \mathrm{ppm}$ attributed to protons of the organic molecules, it not being possible to identify the signals of the three non-equivalent ${ }^{1} \mathrm{H}$ groups. The signals that appear at $\delta^{1} \mathrm{H} \approx 5-6 \mathrm{ppm}$ decrease in intensity when evacuating the TPA-MFI zeolite in the rotor under mild conditions $\left(100{ }^{\circ} \mathrm{C}, 10 \mathrm{~h}\right.$, see TPA-MFI in Figure $6 \mathrm{~b}$ ) and are assigned to physisorbed or occluded water in the material. The signal at $\delta^{1} \mathrm{H}=10.5 \mathrm{ppm}$ due to connectivity defects [67] $\left(\mathrm{SiO}^{-} \ldots \mathrm{HOSi}\right)$ increases its intensity as the amount of TPP in the zeolite increases. This phenomena is totally in agreement with the evolution of the F/OSDA ratio, which decreases as the $\mathrm{P}$ content increases, as shown in Table 2, as previously reported for the TEA/TEP system [64].

The fluorine distribution in the zeolites was analyzed by ${ }^{19} \mathrm{~F}$ MAS NMR spectroscopy. The spectra are shown in Figure 7a and consist of two signals which appear at $\delta^{19} \mathrm{~F}=-64.4 \mathrm{ppm}$ and $\delta^{19} \mathrm{~F}=-80.0 \mathrm{ppm}$. The deconvolution of the spectra, using DMFit software [68], requires two components for the signal which appear at higher chemical shifts and a unique component for the signal at lower chemical shifts as shown for the zeolite TPP-MFI in Figure 7a. The first one is asymmetric, and is attributed to fluorine in a dynamic situation (forming and breaking bond) between two Si atoms in the T9 position of the $t$-mel subunit of MFI structure [62,63]. Another signal appears at $\delta^{19} \mathrm{~F}=-80.0 \mathrm{ppm}$ with a relative intensity that depends on the amount of TPP incorporated, being more pronounced at higher TPP loadings; the total amount of fluorine decreases in the same direction.

The ${ }^{19} \mathrm{~F}$ MAS NMR spectra (Figure 7a) were simulated using two components for the signal at $\delta^{19} \mathrm{~F}=-64.4 \mathrm{ppm}$ and a single component for the signal appearing at $\delta^{19} \mathrm{~F}=-80.0 \mathrm{ppm}$. The results show that the relative proportion of the signal at $-80.0 \mathrm{ppm}$ is $6.9 \%$ (TPA-MFI), $9.7 \%$ (TPX-MFI 25 ), $12.3 \%$ (TPX-MFI ${ }_{45}$ ), and $18.8 \%$ (TPP-MFI) of the total fluorine; that is, it increases as the TPP content in the zeolites increases. Previously, this signal $\left(\delta^{19} \mathrm{~F}=-80.0 \mathrm{ppm}\right)$ has been associated with the different interaction of fluorine atoms with dicationic OSDAs or the presence of defects [69-71]. The results obtained in this work support the last interpretation and seem to be related with the increment of the structural defects with the increase of the TPP content in the samples. This is in agreement with the TEA/TEP system in which the amount of total fluorine also decreases when using P-based OSDAs (see Table 2) and confirms the increase of the proportion of framework connectivity defects as the P incorporated in the zeolite increases [64]. 

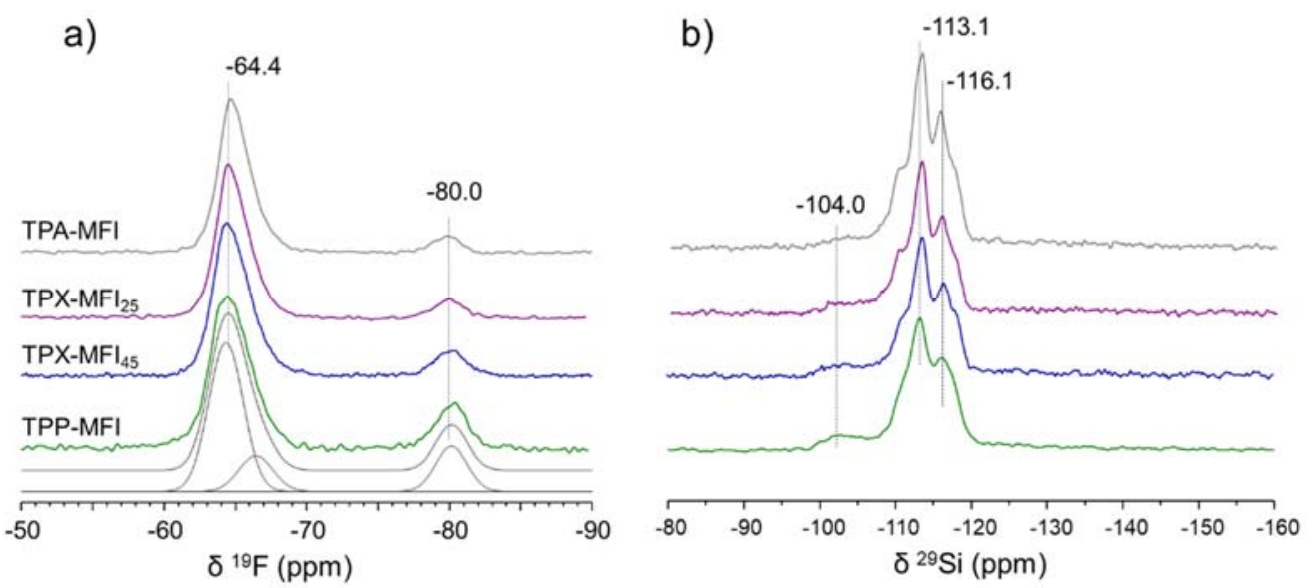

Figure 7. ${ }^{19} \mathrm{~F}$ and ${ }^{29} \mathrm{Si}$ MAS NMR spectra of silicalite- 1 samples synthesized using different OSDAs: (a) ${ }^{19}$ F MAS NMR of the zeolites prepared with TPA, TPP (including the deconvolution of the spectra) and mixtures of them; (b) ${ }^{29} \mathrm{Si}$ MAS NMR of the same zeolites.

The characterization of the zeolite framework was done by measuring the ${ }^{29} \mathrm{Si}$ MAS NMR spectra, which can be seen in Figure $7 \mathrm{~b}$. The spectra are all similar exhibiting four main bands in the $\mathrm{Q}^{4}$ range ( -108 to $-120 \mathrm{ppm}$ ) that become broader when the TPP content in the zeolites increases due to the presence of a higher proportion of defects, as confirmed by the band at $\delta^{29} \mathrm{Si} \approx-104 \mathrm{ppm}$ attributed to zeolitic connectivity defects. The ${ }^{29} \mathrm{Si}$ MAS NMR spectra of the zeolites synthesized do not show the typical doublet attributed to pentacoordinated silicon due to the dynamic nature of the fluorine jumping between two crystallographic positions as previously described in the literature [62,63].

\subsubsection{Characterization of the Interactions OSDA-Zeolite by Bidimensional NMR}

The interactions of the zeolite framework with the organic molecules can be studied by using heteronuclear or homonuclear bidimensional NMR experiments. Figure 8 shows the ${ }^{1} \mathrm{H}^{3}{ }^{31} \mathrm{P} 2 \mathrm{D}$ HETCOR MAS NMR experiment of the TPP-MFI sample containing two main correlation signals at $\delta^{31} \mathrm{P}_{-}{ }^{1} \mathrm{H} \approx(29.9,1.4)$ and $\delta^{31} \mathrm{P}_{-}{ }^{1} \mathrm{H} \approx(29.9,10.4) \mathrm{ppm}$, corresponding to the interactions of the ${ }^{31} \mathrm{P}$ atom with the ${ }^{1} \mathrm{H}$ of the organic molecule and with the connectivity defects, respectively. The last correlation suggests that the zeolitic defects should be located close to the positively charged organic molecule.

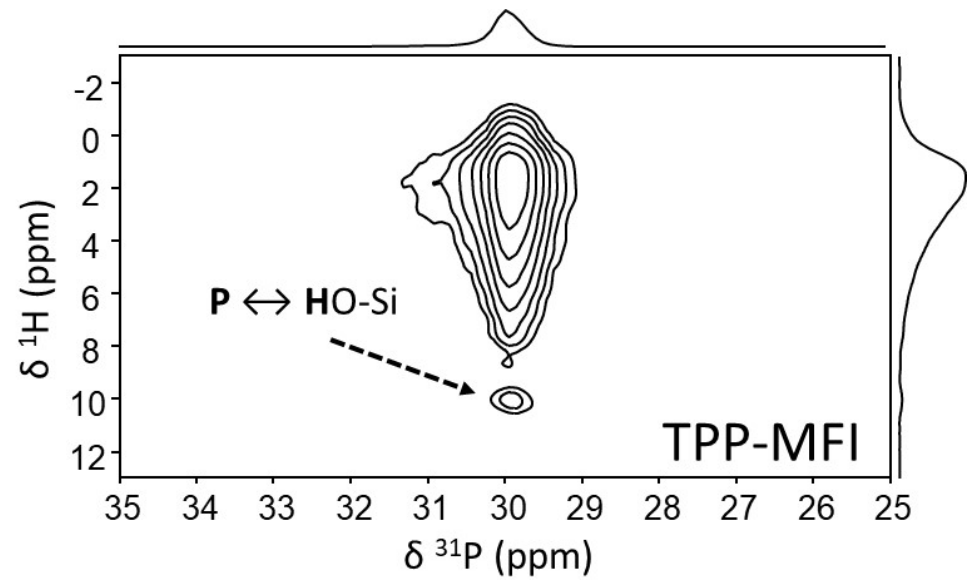

Figure 8. ${ }^{1} \mathrm{H}^{31} \mathrm{P}$ 2D HETCOR NMR experiment of the silicalite-1 zeolite synthesized with TPP.

To get a better knowledge of the location of the zeolitic defects in the MFI channels, the ${ }^{1} \mathrm{H}$ 2D DQ-SQ MAS NMR spectra were measured for the zeolites containing just one type of organic cation. The DQ-SQ experiments are based on homonuclear dipolar interactions and require at least two ${ }^{1} \mathrm{H}$ atoms in a very close proximity to observe the signal; the 
chemical shift in the second dimension is equal to the sum of the chemical shifts of the signals observed in the first dimension $[66,72,73]$.

The ${ }^{1} \mathrm{H}$ 2D DQ-SQ NMR spectra of TPP-MFI and TPA-MFI samples are shown in Figure $9 \mathrm{a}, \mathrm{b}$ which are very similar. The spectra show three correlation signals: (1) a very intense and wide one at $\delta^{1} \mathrm{H}_{-}{ }^{1} \mathrm{H} \approx(1.2,2.4) \mathrm{ppm}$ that includes the auto-correlation signals of protons of the same group and of different groups of the alkyl chains; (2) the signal at $\delta^{1} \mathrm{H}^{-}{ }^{1} \mathrm{H} \approx(10.4,20.8) \mathrm{ppm}$ is the auto-correlation of the connectivity defects in the zeolite, indicating that the $\mathrm{SiO}^{-}$group is close to, at least, two $\mathrm{SiOH}$ groups; and (3) a weak correlation signal is seen at $\delta^{1} \mathrm{H}^{-1} \mathrm{H} \approx(1.2,11.6) \mathrm{ppm}$, which is attributed to the interaction of $\mathrm{SiOH}$ zeolitic defects with $-\mathrm{CH}_{3}$ groups exclusively. This result indicates that the zeolitic defects are much closer to the methyl groups, unlike what was observed through the NOESY or DQ-SQ NMR experiments for the zeolites synthesized with TEA [64,66], where the correlation with all the ${ }^{1} \mathrm{H}$ of the organic cation was seen.
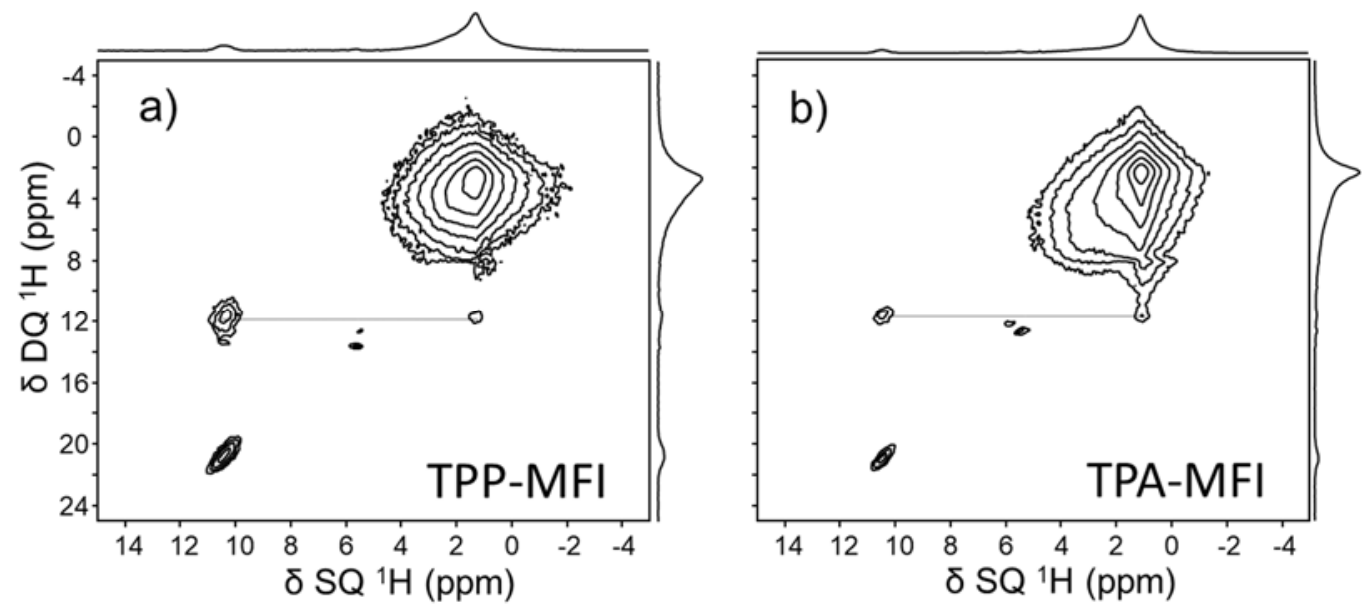

Figure 9. ${ }^{1} \mathrm{H}$ 2D DQ-SQ NMR spectra of (a) TPP-MFI and (b) TPA-MFI silicalite-1 zeolites.

The nature of the framework connectivity defects formed in zeolites with F/OSDA ratios below 1 is a question that is under discussion, since the formation, location, and number of $\mathrm{SiOH}$ groups that are located close to the $\mathrm{SiO}^{-}$species remain unclear. Currently, two models are accepted, the first one proposes two $\mathrm{SiOH}$ groups around two $\mathrm{SiO}^{-}$groups in nanocrystalline silicalite- 1 , and the second model assumes the presence of three $\mathrm{SiOH}$ surrounding the $\mathrm{SiO}^{-}$group in zeolites conventionally synthesized without $\mathrm{F}[67,72-74]$. The results obtained here do not allow us to undoubtedly confirm whether these samples correspond to one model or the other.

The bidimensional NMR study has shown that structural defects are placed close to the OSDA as shown by ${ }^{1} \mathrm{H}^{31} \mathrm{P}$ 2D HETCOR. Moreover, much better understanding is gained by ${ }^{1} \mathrm{H}$ 2D DQ-SQ NMR results, which indicate that the zeolitic defects are located near the methyl groups of the OSDA, as previously reported for the silicalite- 1 zeolite synthesized by the $\mathrm{OH}^{-}$route, and also in the close vicinity of at least two silanol groups.

\section{Conclusions}

Synthesis of silicalite- 1 zeolites using the dual-template procedure with TPA and TPP cations is feasible and both OSDAs are filling the pores of the zeolite framework without any specific preference for any of them, differently to that observed for the TEA/TEP system. In addition, both OSDAs are homogenously mixed inside of the zeolite voids as evidenced by ${ }^{13} \mathrm{C}$ and ${ }^{31} \mathrm{P}$ MAS NMR spectra. The presence of TPP promotes the formation of structural defects, due to a less $\mathrm{F}$ incorporation, raising the concentration of silanol groups in the silicalite- 1 zeolites. Detailed NMR results indicated that structural defects are close to the $\mathrm{CH}_{3}$ group of the entrapped OSDAs in the zeolite, and these defects consist of at least two silanol groups. 
Author Contributions: Conceptualization and Project Administration, F.R.; Investigation, J.M.-O., J.S. and J.A.V.-M.; Writing—original draft preparation, S.V. and J.M.-O.; Writing—review and editing, all authors; Supervision, S.V., T.B. and F.R. All authors have read and agreed to the published version of the manuscript.

Funding: This research was funded by Spanish Ministry of Sciences, Innovation and Universities (MCIU), State Research Agency (AEI), and the European Fund for Regional Development (FEDER) via projects RTI2018-101784-B-I00 and Program Severo Ochoa SEV-2016-0683. J.M.-O. was founded through the Severo Ochoa Program for a predoctoral fellowship SEV-2012-0267-02.

Institutional Review Board Statement: Not applicable.

Informed Consent Statement: Not applicable.

Data Availability Statement: The data presented in this study are available on request from the corresponding authors.

Acknowledgments: The Electron Microscopy Service of the UPV is acknowledged for their help in sample characterization.

Conflicts of Interest: The authors declare no conflict of interest.

\section{References}

1. Barrer, R.M. Zeolites and Clay Minerals as Sorbents and Molecular Sieves; Academic Press: London, UK; New York, NY, USA, 1978.

2. Breck, D.W. Zeolite Molecular Sieves: Structure, Chemistry, and Use; Wiley: New York, NY, USA; London, UK, 1973.

3. Flanigen, E.M. Zeolites and molecular sieves: An historical perspective. In Studies in Surface Science and Catalysis; Elsevier: Amsterdam, The Netherlands, 2001; Chapter 2; Volume 137, pp. 11-35.

4. Cejka, J.; Corma, A.; Zones, S. Zeolites and Catalysis: Synthesis, Reactions and Applications; John Wiley \& Sons: Weinheim, Germany, 2010.

5. Millini, R.; Zou, X.; Strohmaier, K.; Schwieger, W.; Eliasova, P.; Morris, R.E.; Weckhuysen, B.; Zhou, W.; Abdo, S.; Martinez, A. Zeolites in Catalysis: Properties and Applications; Royal Society of Chemistry: London, UK, 2017.

6. Davis, M.E. Zeolites from a Materials Chemistry Perspective. Chem. Mater. 2014, 26, 239-245. [CrossRef]

7. Pérez-Botella, E.; Palomino, M.; Valencia, S.; Rey, F. Zeolites and Other Adsorbents. In Nanoporous Materials for Gas Storage; Kaneko, K., Rodríguez-Reinoso, F., Eds.; Springer: Singapore, 2019; pp. 173-208.

8. Zhang, S.; Pang, L.; Chen, Z.; Ming, S.; Dong, Y.; Liu, Q.; Liu, P.; Cai, W.; Li, T. Cu/SSZ-13 and Cu/SAPO-34 catalysts for deNOx in diesel exhaust: Current status, challenges, and future perspectives. Appl. Catal. A Gen. 2020, 607, 117855. [CrossRef]

9. Database of Zeolite Structures. Available online: http:/ / www.iza-structure.org/databases/ (accessed on 30 April 2021).

10. Corma, A. Inorganic Solid Acids and Their Use in Acid-Catalyzed Hydrocarbon Reactions. Chem. Rev. 1995, 95, 559-614. [CrossRef]

11. Corma, A. From Microporous to Mesoporous Molecular Sieve Materials and Their Use in Catalysis. Chem. Rev. 1997, 97, 2373-2420. [CrossRef] [PubMed]

12. Corma, A.; Martínez, A. Zeolites in refining and petrochemistry. Stud. Surf. Sci. Catal. 2005, 157, 337-366.

13. Vermeiren, W.; Gilson, J.-P. Impact of Zeolites on the Petroleum and Petrochemical Industry. Top. Catal. 2009, 52, 1131-1161. [CrossRef]

14. Saab, R.; Polychronopoulou, K.; Zheng, L.; Kumar, S.; Schiffer, A. Synthesis and performance evaluation of hydrocracking catalysts: A review. J. Ind. Eng. Chem. 2020, 89, 83-103. [CrossRef]

15. Barrer, R.M. Hydrothermal Chemistry of Zeolites; Academic Press: London, UK; New York, NY, USA, 1982.

16. Cundy, C.S.; Cox, P.A. The Hydrothermal Synthesis of Zeolites: History and Development from the Earliest Days to the Present Time. Chem. Rev. 2003, 103, 663-702. [CrossRef]

17. Cundy, C.S.; Cox, P.A. The hydrothermal synthesis of zeolites: Precursors, intermediates and reaction mechanism. Microporous Mesoporous Mater. 2005, 82, 1-78. [CrossRef]

18. Grand, J.; Awala, H.; Mintova, S. Mechanism of zeolites crystal growth: New findings and open questions. CrystEngComm 2016, 18, 650-664. [CrossRef]

19. Flanigen, E.M.; Patton, R.L. Silica Polymorph and Process for Preparing Same. U.S. Patent No. 4,073,865, 14 February 1978.

20. Guth, J.L.; Kessler, H.; Wey, R. New Route to Pentasil-Type Zeolites Using a Non Alkaline Medium in the Presence of Fluoride Ions. In Studies in Surface Science and Catalysis; Murakami, Y., Iijima, A., Ward, J.W., Eds.; Elsevier: Amsterdam, The Netherlands, 1986; pp. 121-128.

21. Camblor, M.A.; Corma, A.; Valencia, S. Spontaneous nucleation and growth of pure silica zeolite- $\beta$ free of connectivity defects. Chem. Commun. 1996, 20, 2365-2366. [CrossRef]

22. Camblor, M.Á.; Villaescusa, L.A.; Díaz-Cabañas, M.J. Synthesis of all-silica and high-silica molecular sieves in fluoride media. Top. Catal. 1999, 9, 59-76. [CrossRef] 
23. Sastre, G.; Vidal-Moya, J.A.; Blasco, T.; Rius, J.; Jorda, J.L.; Navarro, M.T.; Rey, F.; Corma, A. Preferential Location of Ge Atoms in Polymorph C of Beta Zeolite (ITQ-17) and Their Structure-Directing Effect: A Computational, XRD, and NMR Spectroscopic Study. Angew. Chem. Int. Ed. 2002, 41, 4722-4726. [CrossRef]

24. Lobo, R.F.; Zones, S.I.; Davis, M.E. Structure-Direction in Zeolite Synthesis. Top. Incl. Sci. 1995, 21, 47-78. [CrossRef]

25. Burton, A.W.; Zones, S.I. Organic Molecules in Zeolite Synthesis: Their Preparation and Structure-Directing Effects. In Introduction to Zeolite Science and Practice, 3rd ed.; Cejka, J., van Bekkum, H., Corma, A., Schüth, F., Eds.; Elsevier: Amsterdam, The Netherlands, 2007; pp. 137-179.

26. Moliner, M.; Rey, F.; Corma, A. Towards the Rational Design of Efficient Organic Structure-Directing Agents for Zeolite Synthesis. Angew. Chem. Int. Ed. 2013, 52, 13880-13889. [CrossRef]

27. Rey, F.; Simancas, J. Beyond Nitrogen OSDAs. In Insights into the Chemistry of Organic Structure-Directing Agents in the Synthesis of Zeolitic Materials; Gómez-Hortigüela, L., Ed.; Springer International Publishing: Cham, Switzerland, 2017; pp. $103-138$.

28. Burton, A. Recent trends in the synthesis of high-silica zeolites. Catal. Rev. 2018, 60, 132-175. [CrossRef]

29. Corma, A.; Diaz-Cabanas, M.J.; Jorda, J.L.; Rey, F.; Sastre, G.; Strohmaier, K.G. A Zeolitic Structure (ITQ-34) with Connected 9- and 10-Ring Channels Obtained with Phosphonium Cations as Structure Directing Agents. J. Am. Chem. Soc. 2008, 130, 16482-16483. [CrossRef] [PubMed]

30. Dorset, D.L.; Kennedy, G.J.; Strohmaier, K.G.; Diaz-Cabañas, M.J.; Rey, F.; Corma, A. P-Derived Organic Cations as StructureDirecting Agents: Synthesis of a High-Silica Zeolite (ITQ-27) with a Two-Dimensional 12-Ring Channel System. J. Am. Chem. Soc. 2006, 128, 8862-8867. [CrossRef] [PubMed]

31. Rodríguez, M.H.; Jorda, J.L.; Rey, F.; Corma, A. Synthesis and Structure Determination of a New Microporous Zeolite with Large Cavities Connected by Small Pores. J. Am. Chem. Soc. 2012, 134, 13232-13235. [CrossRef] [PubMed]

32. Simancas, R.; Dari, D.; Velamazán, N.; Navarro, M.T.; Cantín, A.; Jordá, J.L.; Sastre, G.; Corma, A.; Rey, F. Modular Organic Structure-Directing Agents for the Synthesis of Zeolites. Science 2010, 330, 1219. [CrossRef] [PubMed]

33. Simancas, R.; Jordá, J.L.; Rey, F.; Corma, A.; Cantín, A.; Peral, I.; Popescu, C. A New Microporous Zeolitic Silicoborate (ITQ-52) with Interconnected Small and Medium Pores. J. Am. Chem. Soc. 2014, 136, 3342-3345. [CrossRef] [PubMed]

34. Yun, Y.; Hernández, M.; Wan, W.; Zou, X.; Jordá, J.L.; Cantín, A.; Rey, F.; Corma, A. The first zeolite with a tri-directional extra-large 14-ring pore system derived using a phosphonium-based organic molecule. Chem. Commun. 2015, 51, 7602-7605. [CrossRef] [PubMed]

35. Maruo, T.; Yamanaka, N.; Tsunoji, N.; Sadakane, M.; Sano, T. Facile Synthesis of AEI Zeolites by Hydrothermal Conversion of FAU Zeolites in the Presence of Tetraethylphosphonium Cations. Chem. Lett. 2014, 43, 302-304. [CrossRef]

36. Degnan, T.; Chitnis, G.; Schipper, P.H. History of ZSM-5 fluid catalytic cracking additive development at Mobil. Microporous Mesoporous Mater. 2000, 35, 245-252. [CrossRef]

37. Vogt, E.T.C.; Weckhuysen, B.M. Fluid catalytic cracking: Recent developments on the grand old lady of zeolite catalysis. Chem. Soc. Rev. 2015, 44, 7342-7370. [CrossRef]

38. Blasco, T.; Corma, A.; Martínez-Triguero, J. Hydrothermal stabilization of ZSM- 5 catalytic-cracking additives by phosphorus addition. J. Catal. 2006, 237, 267-277. [CrossRef]

39. Bleken, F.L.; Chavan, S.; Olsbye, U.; Boltz, M.; Ocampo, F.; Louis, B. Conversion of methanol into light olefins over ZSM-5 zeolite: Strategy to enhance propene selectivity. Appl. Catal. A Gen. 2012, 447-448, 178-185. [CrossRef]

40. Zhang, M.; Xu, S.; Wei, Y.; Li, J.; Wang, J.; Zhang, W.; Gao, S.; Liu, Z. Changing the balance of the MTO reaction dual-cycle mechanism: Reactions over ZSM-5 with varying contact times. Chin. J. Catal. 2016, 37, 1413-1422. [CrossRef]

41. Yokoi, T.; Mochizuki, H.; Namba, S.; Kondo, J.N.; Tatsumi, T. Control of the Al Distribution in the Framework of ZSM-5 Zeolite and Its Evaluation by Solid-State NMR Technique and Catalytic Properties. J. Phys. Chem. C 2015, 119, 15303-15315. [CrossRef]

42. Yokoi, T.; Mochizuki, H.; Biligetu, T.; Wang, Y.; Tatsumi, T. Unique Al Distribution in the MFI Framework and Its Impact on Catalytic Properties. Chem. Lett. 2017, 46, 798-800. [CrossRef]

43. Biligetu, T.; Wang, Y.; Nishitoba, T.; Otomo, R.; Park, S.; Mochizuki, H.; Kondo, J.N.; Tatsumi, T.; Yokoi, T. Al distribution and catalytic performance of ZSM-5 zeolites synthesized with various alcohols. J. Catal. 2017, 353, 1-10. [CrossRef]

44. Dedecek, J.; Balgová, V.; Pashkova, V.; Klein, P.; Wichterlova, B. Synthesis of ZSM-5 Zeolites with Defined Distribution of Al Atoms in the Framework and Multinuclear MAS NMR Analysis of the Control of Al Distribution. Chem. Mater. 2012, 24, 3231-3239. [CrossRef]

45. Pashkova, V.; Sklenak, S.; Klein, P.; Urbanova, M.; Dědeček, J. Location of Framework Al Atoms in the Channels of ZSM-5: Effect of the (Hydrothermal) Synthesis. Chem. Eur. J. 2016, 22, 3937-3941. [CrossRef] [PubMed]

46. Dědeček, J.; Tabor, E.; Sklenak, S. Tuning the Aluminum Distribution in Zeolites to Increase their Performance in Acid-Catalyzed Reactions. ChemSusChem 2019, 12, 556-576. [CrossRef]

47. Kaarsholm, M.; Joensen, F.; Nerlov, J.; Cenni, R.; Chaouki, J.; Patience, G.S. Phosphorous modified ZSM-5: Deactivation and product distribution for MTO. Chem. Eng. Sci. 2007, 62, 5527-5532. [CrossRef]

48. Song, Y.; Zhang, L.-L.; Li, G.-D.; Shang, Y.-S.; Zhao, X.-M.; Ma, T.; Zhang, L.-M.; Zhai, Y.; Gong, Y.-J.; Xu, J.; et al. ZSM-5 extrudates modified with phosphorus as a super effective MTP catalyst: Impact of the acidity on binder. Fuel Process. Technol. 2017, 168, 105-115. [CrossRef]

49. Manrique, C.; Guzmán, A.; Solano, R.; Echavarría, A. Phosphorous-Modified Beta Zeolite and Its Performance in Vacuum Gas Oil Hydrocracking Activity. Energy Fuels 2019, 33, 3483-3491. [CrossRef] 
50. Van Der Bij, H.E.; Aramburo, L.R.; Arstad, B.; Dynes, J.J.; Wang, J.; Weckhuysen, B.M. Phosphatation of Zeolite H-ZSM-5: A Combined Microscopy and Spectroscopy Study. ChemPhysChem 2014, 15, 283-292. [CrossRef] [PubMed]

51. van der Bij, H.E.; Weckhuysen, B.M. Phosphorus promotion and poisoning in zeolite-based materials: Synthesis, characterisation and catalysis. Chem. Soc. Rev. 2015, 44, 7406-7428. [CrossRef] [PubMed]

52. Danisi, R.M.; Schmidt, J.E.; Paioni, A.L.; Houben, K.; Poplawsky, J.D.; Baldus, M.; Weckhuysen, B.M.; Vogt, E.T.C. Revealing long- and short-range structural modifications within phosphorus-treated HZSM-5 zeolites by atom probe tomography, nuclear magnetic resonance and powder X-ray diffraction. Phys. Chem. Chem. Phys. 2018, 20, 27766-27777. [CrossRef]

53. de Menezes, S.C.; Lam, Y.; Damodaran, K.; Pruski, M. Modification of H-ZSM-5 zeolites with phosphorus. 1. Identification of aluminum species by ${ }^{27} \mathrm{Al}$ solid-state NMR and characterization of their catalytic properties. Microporous Mesoporous Mater. 2006, 95, 286-295. [CrossRef]

54. Damodaran, K.; Wiench, J.; de Menezes, S.C.; Lam, Y.; Trébosc, J.; Amoureux, J.P.; Pruski, M. Modification of H-ZSM-5 zeolites with phosphorus. 2. Interaction between phosphorus and aluminum studied by solid-state NMR spectroscopy. Microporous Mesoporous Mater. 2006, 95, 296-305. [CrossRef]

55. Kakiuchi, Y.; Yamasaki, Y.; Tsunoji, N.; Takamitsu, Y.; Sadakane, M.; Sano, T. One-pot Synthesis of Phosphorus-modified AEI Zeolites Derived by the Dual-template Method as a Durable Catalyst with Enhanced Thermal/Hydrothermal Stability for Selective Catalytic Reduction of NOx by $\mathrm{NH}_{3}$. Chem. Lett. 2016, 45, 122-124. [CrossRef]

56. Tsunoji, N.; Tsuchiya, K.; Nakazawa, N.; Inagaki, S.; Kubota, Y.; Nishitoba, T.; Yokoi, T.; Ohnishi, T.; Ogura, M.; Sadakane, M.; et al. Multiple templating strategy for the control of aluminum and phosphorus distributions in AFX zeolite. Microporous Mesoporous Mater. 2021, 321, 111124. [CrossRef]

57. Simancas, R.; Chokkalingam, A.; Elangovan, S.P.; Liu, Z.; Sano, T.; Iyoki, K.; Wakihara, T.; Okubo, T. Recent progress in the improvement of hydrothermal stability of zeolites. Chem. Sci. 2021, 12, 7677-7695. [CrossRef]

58. Yamasaki, Y.; Tsunoji, N.; Takamitsu, Y.; Sadakane, M.; Sano, T. Synthesis of phosphorus-modified small-pore zeolites utilizing tetraalkyl phosphonium cations as both structure-directing and phosphorous modification agents. Microporous Mesoporous Mater. 2016, 223, 129-139. [CrossRef]

59. Mitani, E.; Yamasaki, Y.; Tsunoji, N.; Sadakane, M.; Sano, T. Synthesis of phosphorus-modified AFX zeolite using a dualtemplate method with tetraethylphosphonium hydroxide as phosphorus modification agent. Microporous Mesoporous Mater. 2018, 267, 192-197. [CrossRef]

60. Van Koningsveld, H.; Van Bekkum, H.; Jansen, J.C. On the location and disorder of the tetrapropylammonium (TPA) ion in zeolite ZSM-5 with improved framework accuracy. Acta Crystallogr. Sect. B Struct. Sci. 1987, 43, 127-132. [CrossRef]

61. Olson, D.H.; Kokotailo, G.T.; Lawton, S.L.; Meier, W.M. Crystal structure and structure-related properties of ZSM-5. J. Phys. Chem. 1981, 85, 2238-2243. [CrossRef]

62. Koller, H.; Wölker, A.; Villaescusa, L.; Díaz-Cabañas, M.J.; Valencia, S.; Camblor, M. Five-Coordinate Silicon in High-Silica Zeolites. J. Am. Chem. Soc. 1999, 121, 3368-3376. [CrossRef]

63. Fyfe, C.A.; Brouwer, D.H.; Lewis, A.A.R.; Chézeau, J.-M. Location of the Fluoride Ion in Tetrapropylammonium Fluoride Silicalite-1 Determined by ${ }^{1} \mathrm{H} /{ }^{19} \mathrm{~F} /{ }^{29} \mathrm{Si}$ Triple Resonance CP, REDOR, and TEDOR NMR Experiments. J. Am. Chem. Soc. 2001, 123, 6882-6891. [CrossRef]

64. Martinez-Ortigosa, J.; Simancas, J.; Vidal-Moya, J.A.; Gaveau, P.; Rey, F.; Alonso, B.; Blasco, T.; Vidal-Moya, A. Host-Guest and Guest-Guest Interactions of P- and N-Containing Structure Directing Agents Entrapped inside MFI-Type Zeolite by Multinuclear NMR Spectroscopy. J. Phys. Chem. C 2019, 123, 22324-22334. [CrossRef]

65. Dib, E.; Gimenez, A.; Mineva, T.; Alonso, B. Preferential orientations of structure directing agents in zeolites. Dalton Trans. 2015, 44, 16680-16683. [CrossRef] [PubMed]

66. Liu, X.; Luo, Q. Solid State NMR Spectroscopy Studies of the Nature of Structure Direction of OSDAs in Pure-Silica Zeolites ZSM-5 and Beta. J. Phys. Chem. C 2017, 121, 13211-13217. [CrossRef]

67. Koller, H.; Lobo, R.F.; Burkett, S.L.; Davis, M.E. SiO-..HOSi Hydrogen Bonds in As-Synthesized High-Silica Zeolites. J. Phys. Chem. 1995, 99, 12588-12596. [CrossRef]

68. Massiot, D.; Fayon, F.; Capron, M.; King, I.; Le Calvé, S.; Alonso, B.; Durand, J.-O.; Bujoli, B.; Gan, Z.; Hoatson, G. Modelling oneand two-dimensional solid-state NMR spectra. Magn. Reson. Chem. 2002, 40, 70-76. [CrossRef]

69. Rojas, A.; Gómez-Hortigüela, L.; Camblor, M.A. Zeolite Structure Direction by Simple Bis(methylimidazolium) Cations: The Effect of the Spacer Length on Structure Direction and of the Imidazolium Ring Orientation on the ${ }^{19}$ F NMR Resonances. J. Am. Chem. Soc. 2012, 134, 3845-3856. [CrossRef]

70. Lu, P.; Gómez-Hortigüela, L.; Camblor, M.A. Synthesis of pure silica MFI zeolites using imidazolium-based long dications. A comparative study of structure-directing effects derived from a further spacer length increase. Dalton Trans. 2018, 47, 7498-7504. [CrossRef]

71. Losch, P.; Pinar, A.B.; Willinger, M.G.; Soukup, K.; Chavan, S.; Vincent, B.; Pale, P.; Louis, B. H-ZSM-5 zeolite model crystals: Structure-diffusion-activity relationship in methanol-to-olefins catalysis. J. Catal. 2017, 345, 11-23. [CrossRef]

72. Brunklaus, G.; Koller, H.; Zones, S.I. Defect Models of As-Made High-Silica Zeolites: Clusters of Hydrogen-Bonds and Their Interaction with the Organic Structure-Directing Agents Determined from ${ }^{1} \mathrm{H}$ Double and Triple Quantum NMR Spectroscopy. Angew. Chem. Int. Ed. 2016, 55, 14459-14463. [CrossRef] 
73. Dib, E.; Grand, J.; Mintova, S.; Fernandez, C. Structure-Directing Agent Governs the Location of Silanol Defects in Zeolites. Chem. Mater. 2015, 27, 7577-7579. [CrossRef]

74. Shantz, D.F.; der Günne, J.S.A.; Koller, H.; Lobo, R.F. Multiple-Quantum ${ }^{1}$ H MAS NMR Studies of Defect Sites in As-Made All-Silica ZSM-12 Zeolite. J. Am. Chem. Soc. 2000, 122, 6659-6663. [CrossRef] 